\title{
LA RELATIVIDAD LINGÜÍSTICA CLÁSICA Y SUS AVATARES ACTUALES: RAZONES PARA EL ESCEPTICISMO*
}

\author{
Alfonso García SuÁREZ \\ Universidad de Oviedo
}

\begin{abstract}
RESUMEN
Tras la decadencia del relativismo lingüístico en el Zeitgeist universalista de los años 50 y 60, han florecido en las dos últimas décadas diversas variedades de neorrelativismo. A modo de marco, en $\S 2$ se formulan cuatro proposiciones que configuran la versión fuerte, clásica, de la llamada «hipótesis de Sapir-Whorf». Las dificultades que presenta el análisis de Whorf de la pluralidad y el número en inglés y en hopi se introducirán en $\$ 3$ como muestra de las objeciones conceptuales y empíricas a las que está expuesta su posición. $§ 4$ es una presentación parcial del estado actual de la cuestión, centrada en tres dominios en los que se han postulado efectos whorfianos: la hipótesis de Slobin del «pensar para hablar» y su aplicación al dominio de los sucesos de movimiento; la obra de Levinson y sus asociados sobre marcos de referencia espacial; y los estudios de Lucy y sus colaboradores sobre lenguas clasificadoras y la forma y la composición de las entidades. Las objeciones planteadas por los críticos de estas variedades de neorrelativismo dejan hueco para el escepticismo.
\end{abstract}

Palabras clave: relatividad lingüística; relatividad cognitiva; relatividad metafísica; determinismo lingüístico; incomensurabilidad; plural; número; tiempo; objetificación; suceso de movimiento; pensar para hablar; marco de referencia espacial; lengua clasificadora; forma; material; Whorf.

\begin{abstract}
After the decline of linguistic relativism in the universalist Zeitgeist of the 50's and the 60's, several varieties of neorelativism have blossomed in the two last decades. As a scaffolding, four propositions that shape the classical strong version of the so-called «Sapir-Whorf hypothesis» are stated in $§ 2$. The shortcomings in Whorf's analysis of number and plurality in English and Hopi will be introduced in $\S 3$ as a token of the conceptual and empirical objections to which his position is exposed. $\S 4$ is a partial presentation of the state of the art focused on three domains in

* Este trabajo ha sido realizado con la ayuda del proyecto de investigación MEC-HUM200765921. Juan Acero, siempre generoso, me puso en la pista de gran parte de la bibliografía que manejo. Ignacio Bosque se tomó la molestia de leer una primera versión y enviarme extensos comentarios. Un intercambio de opiniones con Rafael Pardo Avellaneda me ayudó a formular con claridad algunas objeciones al experimento mental que propone Slobin sobre el uso de los pronombres de distancia y respeto. Les quedo agradecido.
\end{abstract}


which Whorfian effects have been postulated: Slobin's hypothesis of «thinking for speaking» and its application to the domain of events of movement; the work of Levinson and his associates on spatial frames of reference; and the studies of Lucy and his collaborators on classifier languages and the form and composition of entities. The objections raised by the critics of these varieties of neorelativism leave room for scepticism.

Key Words: linguistic relativity; cognitive relativity; metaphysical relativity; linguistic determinism; incommensurability; plurality; number; time; objectification; event of movement; thinking for speaking; spatial frame of reference; classifier language; form; composition; Whorf.

RECIBIDO: $16 / 10 / 2010$

APROBADO: 14/03/2011

El fenómeno del pensar es algo sumamente misterioso y la mayor luz sobre él de la que disponemos la arroja con mucho el estudio del lenguaje. Ese estudio muestra que las formas de los pensamientos de una persona son controladas por leyes inexorables de cuyos patrones es inconsciente. Esos patrones son la sistematización intrincada y no percibida de su propio lenguaje... Su pensamiento mismo se da en el lenguaje -en inglés, en sánscrito, en chino.

BeNJAMin LeE Whorf

El relativismo conceptual es una doctrina embriagadora y exótica, o lo sería si pudiéramos sacar algo en claro de ella. El problema es que, como tan a menudo en filosofía, es difícil mejorar la inteligibilidad sin perder el entusiasmo.

Donald DAVIDSON

\section{INTRODUCCIÓN}

La hipótesis de la relatividad lingüística formó parte de un conglomerado de ideas con las que los pensadores románticos reaccionaron contra el universalismo y el cosmopolitismo propios de la Ilustración. Su expositor más capaz, Wilhelm von Humboldt, concibió el lenguaje como el órgano formativo del pensamiento ${ }^{1}$. Pero la versión del relativismo lingüístico que mayor influencia posterior ha tenido es la asociada con la obra que desarrollaron entre los años 20 y 40 del siglo pasado los etnolingüistas norteamericanos Edward Sapir y Benjamin Lee Whorf ${ }^{2}$. Fue

\footnotetext{
1 Su trabajo seminal es Humboldt 1836.

${ }^{2}$ Una exposición detallada -y muy favorable- de sus posiciones se puede ver en los capítulos 1 y 2 de Lucy 1992a. En ese libro se encontrará también un detenido estudio de los trabajos empíricos sobre la hipótesis relativista que se han venido desarrollando entre los años 40 y 90 .
} 
este último quien presentó una formulación más elaborada de la hipótesis relativista, una versión que cautivó la imaginación popular y que también tuvo un profundo impacto entre practicantes de diversas disciplinas filosóficas y científicas. Casi desde el primer momento, las ideas de Sapir y de Whorf no pasaron sin detractores. Hubo voces discrepantes desde una perspectiva específicamente conceptual ${ }^{3}$. Pero también los trabajos empíricos que se llevaron a cabo en el dominio del vocabulario para los colores llevaron a resultados no muy halagüeños o al menos nada concluyentes. Tras un paréntesis en el que el relativismo lingüístico cayó en desprestigio ante un nuevo Zeitgeist dominado por el universalismo, el nativismo y el modularismo de cuño chomskyano, el whorfianismo ha vuelto a resurgir en las últimas décadas.

El presente trabajo consta de dos partes. En la primera (\$2), expondré cuatro tesis que configuran lo que podríamos llamar «whorfianismo fuerte», la posición clásica de Sapir y de Whorf, y aludiré a varios textos en los que ambos subscriben inequívocamente esas tesis. Aunque esas cuatro tesis son bien conocidas, tenerlas presentes y diferenciadas nos servirá como marco a las objeciones que plantearé al whorfianismo fuerte $(\S 3)$. La parte segunda del trabajo (§ 4$)$, contiene más elementos expositivos que críticos. Será una presentación del estado actual de la cuestión que atenderá a tres dominios en los que recientemente se han buscado efectos whorfianos sobre la cognición: los sucesos de movimiento (y en relación con ellos la hipótesis del «pensar para hablar» de Dan Slobin); la localización espacial (y en conexión con ella los trabajos de Stephen Levinson y sus asociados sobre los efectos cognitivos de los marcos de referencia espacial explotados por lenguas diversas); y los trabajos de John Lucy y sus colegas sobre los efectos cognitivos de las lenguas clasificadoras en la atención diferencial a la forma o a la composición material de las entidades.

\section{El RELATIVISMO LingÜístico ClÁSICO: LAS TESIS De SAPIR-WHORF}

Cualquier defensor de la relatividad lingüística propugna al menos una doctrina débil que podríamos llamar «la tesis mínima de la relatividad lingüística»:

TMRL: Las estructuras gramaticales de las diversas lenguas se reflejan en ciertos procesos no lingüísticos -cognitivos y/o comportamentales- de sus usuarios.

\footnotetext{
${ }^{3}$ Entre los filósofos fue especialmente influyente la crítica de Max Black recogida en su colección de ensayos de 1962. Entre los sociólogos y los sociolingüistas tuvo cierto impacto el libro de Ferruccio Rossi-Landi de 1973.
} 
Algunos defensores del whorfianismo han formulado la tesis de la relatividad lingüística en esos términos. Un entusiasta expositor ha escrito: «Pocas ideas generan tanto interés y controversia como la hipótesis de la relatividad lingüística, la propuesta según la cual el lenguaje particular que hablamos influye en el modo en que pensamos sobre la realidad» (Lucy 1997, p. 291). Puesta en términos tan generales, la hipótesis parece difícilmente discutible, justo por ser sumamente vaga. Los problemas comienzan cuando forzamos al defensor de la relatividad lingüística a especificar la naturaleza de la relación de influencia y a delimitar sus dos términos: ¿qué componentes semánticos, léxicos o estructurales, son los relevantes?, ¿qué procesos concretos no lingüísticos son los influidos? y, lo que es fundamental, ¿cuál es la naturaleza de esa relación entre componentes lingüísticos y procesos no lingüísticos que se ha descrito vagamente con los verbos reflejarse o influir? $\mathrm{O}$, parafraseando a Davidson, ¿podemos ganar en precisión sin perder el entusiasmo?

Dependiendo en gran medida de las respuestas que se den a esas cuestiones, cabe distinguir variedades de relativismo lingüístico más o menos fuertes. Llamemos «whorfianismo fuerte» a la más estricta. Se trata de la posición que fue defendida por Sapir y por Whorf. El whorfianismo fuerte puede ser caracterizado como una postura configurada por la adhesión a cuatro proposiciones:

(a) la tesis de la relatividad cognitiva,

(b) la tesis del determinismo lingüístico,

(c) la tesis de la relatividad metafísica, y

(d) la tesis de la incomensurabilidad.

\subsection{La tesis de la relatividad cognitiva}

«La tesis de la relatividad cognitiva» ha sido presentada a veces como la conclusión del llamado «silogismo whorfiano»:

P1: Las lenguas varían substancialmente en el modo en que, a través de sus estructuras gramaticales, clasifican o «trocean» el mundo.

P2: Las estructuras gramaticales de las lenguas condicionan la manera en que sus hablantes perciben o conciben en el mundo.

TRC: Luego, hablantes de lenguas que varían substancialmente en sus estructuras gramaticales percibirán o concebirán el mundo de manera diferente.

No hay duda de que el silogismo es válido; si se admiten sus dos premisas, se sigue su conclusión. No obstante, la cuestión es si las premisas son admisibles. Con las adecuadas matizaciones, P1 no parece demasiado discutible en vista de la enorme diversidad existente tanto en las es- 
tructuras léxicas y sintácticas de las lenguas como en las distinciones semánticas que contienen. De hecho, el contacto con lenguas «exóticas», su clasificación taxonómica y su estudio detallado fueron factores decisivos que impresionaron a los propugnadores de la tesis y los llevaron a defenderla.

Todo depende, pues, de P2. Pero, a diferencia de P1, esa segunda premisa es más discutible. Es de notar que Franz Boas, que contribuyó poderosamente a llamar la atención sobre P1, no admitió P2, salvo tal vez ocasionalmente. Pensó, por el contrario, que, aunque lenguas diversas clasifican la experiencia de modos diferentes, esas clasificaciones lingüísticas reflejan pero no condicionan o determinan el pensamiento: hay una «unidad psíquica de la humanidad». Parece incluso que en principio P1 no tiene por qué excluir ciertas formas de innatismo universalista: aun admitiendo que todas las lenguas compartan estructuras subyacentes, no hay duda de que entre ellas hay substanciales diferencias léxicas y estructurales ${ }^{4}$. Sapir y Whorf, en cambio, insistieron en P2. Así, en Carroll 1956, p. 212, se afirma que el sistema gramatical de una lengua no es tan solo un instrumento para transmitir ideas, sino que «forja él mismo las ideas, programa y guía la actividad mental del individuo». Tenemos aquí una forma de relatividad lingüística, consonante con la defendida por Humboldt, que enfatiza que el lenguaje tiene una «función conformadora» del pensamiento.

\subsection{La tesis del determinismo lingüístico}

P2 contiene una cierta dosis de vaguedad: ¿cómo deben entenderse las nociones de «condicionar» o «influir» cuando se afirma que estructuras semánticas no análogas condicionan, o influyen en, formas de cognición no isomórficas? Dependiendo de la clase de respuesta que se dé a esta cuestión, obtenemos otra dimensión para evaluar los grados de fuerza que puede tener el whorfianismo.

Habitualmente, las afirmaciones de Sapir y Whorf van en la línea del determinismo estricto. Sapir habla de la «imposición» del lenguaje sobre la experiencia, de su «control tiránico», de que «estamos a [su] merced» (aunque a veces, un tanto inconsistemente, dice cosas que desmienten que haya una coerción así). Whorf se refiere a sus «leyes inexorables», a sus «cadenas irrompibles» que nos constriñen inconscientemente, pone énfasis en la «obligatoriedad», nos dice que una lengua «fuerza» a sus hablantes a pensar de cierto modo, que la obligatoriedad y la frecuencia de las categorías gramaticales ejercen una «compulsión comportamental»

\footnotetext{
${ }^{4}$ Incluso un universalista tan combativo como Jerry Fodor admite esta compatibilidad: véase al respecto Fodor 1975, p. 85.
} 
(Carroll 1956, pp. 137-38). Todas esas referencias a coerciones, controles férreos, obligatoriedades, etc., indican claramente que Sapir y Whorf sostienen una tesis ulterior, «la tesis del determinismo lingüístico»:

TDL: La manera en que los hablantes perciben o conciben el mundo les es impuesta deterministamente por las estructuras de sus lenguas.

A veces Whorf hace afirmaciones que suenan más matizadas. Por ejemplo, en lugar de hablar de «imposición» u «obligatoriedad», utiliza una terminología más suave: modos de hablar, formas de pensar o concebir habituales, etc. Esto ha sido subrayado por sus admiradores recientes, como Lucy, que tienden a minimizar e incluso a pasar por alto los múltiples pasajes en los que claramente hay un compromiso con TDL.

\subsection{La tesis de la relatividad metafísica}

Adviértase que TRC es una conclusión epistemológica que tiene que ver con nociones cognitivas, como son las de percibir o concebir. Pero Sapir y Whorf van más allá de Boas, no solo porque insisten en P2, sino porque hacen un pronunciamiento adicional, de índole metafísica u ontológica, que podemos denominar «la tesis de la relatividad metafísica»:

TRM: Hablantes de lenguas estructuralmente distintas no viven en un único mundo sino en mundos distintos.

Sapir es tajante al respecto: «Los mundos en los cuales viven sociedades distintas son mundos distintos, no solamente el mismo mundo con etiquetas diferentes» (en Hymes 1949, p. 162). En Whorf encontramos proclamas del mismo tenor: «Nunca dos lenguas son suficientemente semejantes para que se considere que representan la misma realidad social». Aquí Whorf parece limitar el relativismo ontológico a la realidad social, en contradistinción con el reino de la naturaleza. Pero en ocasiones va más lejos: «el 'mundo real' es en gran medida construido sobre la base de los hábitos lingüísticos del grupo» (Carroll 1956, p. 164). Whorf no deja claro cómo debe entenderse ese «en gran medida», pero hay ocasiones en que es claramente más ambicioso: «el mundo se presenta como un flujo caleidoscópico de impresiones que debe ser organizado por nuestras mentes -y esto significa en gran medida por el sistema lingüístico que hay en nuestras mentes» (Carroll 1956, p. 213). O más comprometidamente aún: «los hechos son diferentes para hablantes cuyo trasfondo lingüístico proporciona una forma diferente de formularlos» (Carroll 1956, p. 235).

Una de las consecuencias que extrae Whorf de TRC y TRM es que las categorías de la metafísica occidental -las categorías de substancia, causalidad, etc.- no son universales e indispensables, como supusie- 
ron, entre otros y cada uno a su manera, Aristóteles, Kant y Strawson, sino que son sombras parroquiales proyectadas por las estructuras semánticas de las lenguas de la familia que él denomina SAE (Standard Average European: más o menos, las lenguas indoeuropeas que nos son familiares). Sin embargo, es de notar que este relativismo se mantiene en el plano de los hechos -y por ello exige ser verificable- y no en el plano normativo. Whorf consideraba que algunas lenguas imponen concepciones del mundo más correctas que otras; p. ej., sostenía que el hopi está mejor equipado que el inglés para habérselas con la física contemporánea.

Conviene señalar que, a diferencia de TRC, TRM no se sigue de P1 y P2. En efecto, P1 tiene un alcance ontológico: concierne a la articulación o segmentación semántica del mundo. Pero que diversas lenguas «troceen» el mundo de modo no isomórfico no implica de por sí que no haya un único mundo segmentado por ellas, un único mundo en el que habitan los usuarios de esas lenguas diversas. En cuanto a P2, es una premisa que tiene que ver con un asunto epistemológico, con cómo conciben o perciben el mundo los usuarios de las lenguas, pero no hace ninguna aserción ontológica; en particular, es neutral con respecto a la cuestión de si quienes tienen percepciones o concepciones del mundo diferentes habitan en mundos diferentes. Pero TRM tampoco se sigue de la tesis TRC, incluso en su forma fuerte: aun suponiendo que la Weltanschauung de los usuarios de una lengua les sea impuesta por las categorías gramaticales básicas de esa lengua, no se puede inferir la inexistencia de una única realidad objetiva reflejada de modo distinto en cada Weltanschauung particular. En suma, a pesar de las desmesuradas pretensiones cósmicas de Sapir y de Whorf, de su posición no se sigue en realidad una tesis metafísica, ontológica, tan ambiciosa como TRM. De hecho, no se sigue una tesis metafísica de ningún tipo.

\subsection{La tesis de la incomensurabilidad}

La aceptación de la conjunción de TRC y TRM lleva a admitir un corolario incómodo, la tesis de la incomensurabilidad:

TI: Las diferentes concepciones del mundo que les son impuestas a los hablantes por lenguas substancialmente diversas son incomensurables.

En efecto, si los usuarios de lenguas substancialmente diversas viven en mundos diferentes, no meramente en lugares distintos del mismo mundo, y si esas lenguas fuerzan a sus usuarios a diferir en sus concepciones del mundo, es difícil ver qué base podría existir para una comparación de sus diversas Weltanschauungen: no habría ni conceptos compartidos ni relaciones lógicas entre sus enunciados. 
No hay duda de que tanto Sapir como Whorf subscriben esta tesis. El primero es de nuevo tajante. En Sapir 1931 sostiene que hay una imposición del lenguaje sobre la experiencia y que como resultado lenguajes diferentes llevan a concepciones del mundo incomensurables (en Hymes 1964, p. 128). Whorf, por su parte, habla de visiones del mundo ampliamente divergentes e incluso mutuamente ininteligibles (Carroll 1956, p. 246).

\section{Algunas objeciones AL WHORFIANiSMo FUERTE}

El whorfianismo fuerte, y en particular su formulación más elaborada, la que desarrolló Whorf, es inviable. Examinaré tres tipos de objeciones a las que está sometido. Comenzaré con el estudio de un caso, el análisis contrastivo que hace Whorf de la pluralidad y el tiempo en inglés y en hopi. Tras resumirlo brevemente, señalaré tres dificultades con las que se enfrenta:

(i) confusiones conceptuales,

(ii) dificultades en la noción de objetificación, y

(iii) razonamiento circular.

En segundo lugar, llamaré la atención sobre el hecho de que la posición de Whorf suscita un problema de calibración que amenaza con ser insoluble. Finalmente, y de modo muy breve, sugeriré que el whorfianismo fuerte no es empíricamente controlable.

\subsection{El caso del análisis de Whorf de la pluralidad y el tiempo en inglés y en hopi}

Los análisis contrastivos que hizo Whorf de las estructuras semánticas del hopi y del inglés dejan mucho que desear desde un punto de vista conceptual. Podemos verlo tomando un caso de estudio, su análisis del número y la pluralidad en inglés y en hopi, y de su influencia en sus respectivas concepciones del tiempo. En uno de los artículos clave recogidos en Carroll 1956, «The relation of habitual thought and behavior to language», publicado por primera vez en 1939, Whorf advierte que en inglés (y otras SAEs) los números cardinales y la pluralidad se aplican tanto a plurales reales (p. ej., diez hombres) como a plurales imaginarios (p. ej., diez dias). El contraste real/imaginario apunta a que los primeros son agregados espaciales perceptibles, mientras que las pluralidades imaginarias son agregados metafóricos. Whorf explica:

Diez hombres son o podrían ser percibidos objetivamente como diez... Pero de diez días no podemos tener experiencia objetiva. Tenemos experiencia de 
un solo día, hoy; los otros nueve (o incluso la totalidad de los diez) son algo evocado a partir de la memoria o de la imaginación. Si a diez días se los considera un grupo, debe ser un grupo imaginario, construido mentalmente (apud Carroll 1956, p. 139).

En construcciones como diez dias, sostiene Whorf, describimos secuencias cíclicas, el paso de las semanas, los meses, los años, etc., objetificándolas -tratando agregados imaginarios como si fueran conjuntos perceptibles de objetos que pueden ser contados y medidos a la manera de los objetos tangibles que tienen una forma y una substancia-. El tratamiento de una entidad imaginaria, el tiempo, como si fuera un objeto perceptible surge porque en inglés, y en general en las lenguas SAE, los patrones de número gramatical categorizan del mismo modo dos clases distintas de experiencia, la de lo objetivo y la de lo imaginario. De este modo, los hablantes de lenguas SAE somos llevados por estos patrones a buscar una substancia asociada con un día, un mes, un año, etc., una substancia que identificamos con una noción abstracta de tiempo y que concebimos como una entidad continua, homogénea e informe. Tenemos aquí un caso en el que una analogía gramatical produce una identificación conceptual.

Whorf observa que la analogía lingüística que se da en inglés entre agregados perceptibles y secuencias cíclicas no es de carácter necesario, pues en hopi los cardinales y los plurales se usan solo para entidades agrupables en grupos objetivos; no hay plurales imaginarios y el tiempo es contado mediante ordinales unidos a substantivos en singular (p. ej., en hopi no se diría permanecieron diez días sino permanecieron hasta el día undécimo). Whorf concluyó que los hopi conciben el tiempo de modo distinto que los hablantes de SAEs. La lengua hopi no trata el flujo de tiempo como una fila de casos contables, como diez dias, sino como un único proceso. Aunque reconoció que los hopi tienen palabras para expresar lo que nosotros concebiríamos como ciclos temporales -días, meses, años, etc.-, sostuvo que su estructuración formal en la gramática no les lleva a buscar la noción abstracta de tiempo que tenemos nosotros.

Aun admitiendo que lo anterior es un mero resumen apretado de los puntos de vista de Whorf y deja de lado ingredientes interesantes, creo que basta para mostrar que su análisis está abierto a cuando menos tres objeciones de índole conceptual.

\subsubsection{Dificultades en la noción whorfiana de experiencia objetiva}

Whorf se revela un filósofo penoso cuando emplea en este análisis las nociones de "percibir» o «experienciar»-valga el expresivo aunque feo anglicismo-. Decimos: desde hace diez días vengo experimentando un continuo dolor de muelas. Al hacer este enunciado nos basamos tanto en la 
experiencia inmediata del momento presente, en la experiencia del dolor actual, como en la memoria, en el recuerdo del dolor pasado ¿iSe trata entonces de un plural «real», de un plural «imaginario» o de ambas cosas a la vez? No creo que Whorf pudiera dar una respuesta aceptable a esta pregunta. Además, la memoria misma es una forma de experiencia, no en este caso de mi dolor de muelas actual sino de mi dolor de muelas pasado. Y, a menos que la memoria me juegue una mala pasada, no tiene por qué haber nada de imaginario o de mentalmente construido en el persistente dolor que me lleva torturando diez días. Fue tan molestamente real como el dolor que siento ahora.

Podría sentirse la tentación de responder a esta objeción que el enunciado anterior es descomponible en dos: siento hoy dolor de muelas y sentí dolor de muelas los nueve días anteriores. Y podría alegarse whorfianamente que, mientras que, como es obvio, en el primero no hay plural ninguno relevante, en el segundo hay un plural imaginario; imaginario, porque solo tengo experiencia del día actual y el dolor de los nueve días pasados es meramente evocado en la memoria o en la imaginación. Pero el problema está en que Whorf no deja claro lo que quiere decir cuando afirma que diez días no pueden ser objetivamente experienciados. ¿Qué entiende por 'experienciar objetivamente'? Si se trata de lo que él considera que es percibir objetivamente, algo que admite que es posible en el caso de agregados espaciales, no está claro que el hoy sea algo que pueda ser objeto de esa clase de percepción. En el sentido en el que puedo tener experiencia objetiva de diez hombres -podría ver diez hombres juntos en la esquina de la calle, por tomar el ejemplo del propio Whorf-, no puedo experienciar el hoy: los instantes que forman el día de hoy no pueden ser unidos en un grupo perceptible; por los criterios de Whorf, solo puedo percibir objetivamente el momento presente. Por tanto, por esos mismos criterios, los instantes pasados del día de hoy, no digamos ya los instantes futuros, son sacados de la memoria o de la imaginación. Considerado como grupo, el conjunto de los instantes del día de hoy tendría que ser, si seguimos coherentemente a Whorf, un grupo imaginario, construido mentalmente. Cuando en la cita anterior Whorf dice que no solo los otros nueve días, sino «incluso la totalidad de los diez», es algo evocado en la memoria o en la imaginación tal vez esté reconociendo lo que acabo de señalar: que si admitimos que del pasado en general no tenemos experiencia objetiva, tampoco estamos autorizados a decir que la tenemos de los instantes pasados del día de hoy. Pero esto tendría la consecuencia incómoda de que Whorf se habría comprometido con la tesis implausible de que solo es real u objetivo lo que experimentamos sensorialmente en el momento presente; lo pasado, incluyendo los sucesos de hace un instante, es irreal, es un mero constructo mental. Una conclusión que podría ponernos en la pendiente resbaladiza del solipsismo del momento presente. 


\subsubsection{Dificultades en la noción whorfiana de «objetificación»}

En las lenguas SAE también usamos para las secuencias cíclicas ordinales que se ajustan al patrón que Whorf advirtió; p. ej., después del sexto día Dios descansó. Ciertamente, se trata de un recurso opcional, mientras que, si Whorf es fiable, en hopi es obligatorio. ¿Pero qué muestra esto? ¿Que ellos no objetifican el tiempo, que nosotros lo objetificamos unas veces y no otras o, como es más plausible, que una lengua puede ser más flexible y ofrecer recursos para contar secuencias cíclicas de dos maneras, bien con cardinales o bien con ordinales, sin que de ello puedan extraerse implicaciones metafísicas?

Tal vez pudiera pensarse que Whorf advirtió agudamente un fenómeno real, pero careció de una distinción semántica apropiada para formularlo de modo aceptable. ¿No pudo querer decir que un substantivo como día no es en hopi un término contable sino un término no contable, un término de masa? Una conjetura así parece quedar desmentida por el hecho de que dentro del trabajo de 1939 (publicado en 1941), «The relation of habitual thought and behavior to language» (en Carroll 1956, pp. 134-159), inmediatamente después de la sección que estamos comentando, hay otra, titulada «Nouns of physical quantity in SAE and Hopi» (Carroll 1956, pp. 140-142), en la que Whorf, que tal vez conociera la obra de Jespersen, introduce la distinción entre individual nouns y mass nouns. Los primeros son justamente los que en terminología actual llamamos «nombres contables». Y tanto los ejemplos de unos y otros nombres como los rasgos diferenciales que ofrece son precisamente los que hoy encontramos en cualquier gramática al uso. Curiosamente, Whorf introduce la distinción diciendo que «[tenemos] dos clases de nombres denotativos de cosas físicas» (Carroll 1956, p. 140; énfasis añadido) y los únicos ejemplos que da en la sección en cuestión son de entidades materiales. Sin embargo, la distinción contable/de masa vale también para entidades abstractas - música y sabiduría no son contables, conjunto y entidad lo son.

Tras introducir la distinción y ejemplificarla con nombres de cosas físicas, Whorf pasa a afirmar que en hopi no hay una subclase formal de nombres de masa: «Todos los nombres tienen un sentido individual y tanto formas singulares como plurales» (Carroll 1956, p. 141). Sin embargo, a pesar de que parece restringir la distinción individual/de masa a entidades materiales, en la sección siguiente, «Phases of cycles in SAE and Hopi», observa que en las SAE los nombres de fases cíclicas, verano, septiembre, atardecer, etc., se comportan gramaticalmente como nombres de objetos físicos -al cambio, como nombres contables- y ese comportamiento nos lleva a una objetificación de los procesos cíclicos temporales y a la postulación de un ítem amorfo, el tiempo. Por el contrario, continúa señalando, «en su totalidad los términos de fase en hopi... no son 
nombres sino una especie de adverbios» (Carroll 1956, p. 143), de modo que cuando es mañana o mientras está ocurriendo la fase-mañana serían traducciones aproximadas de lo que nosotros expresaríamos con en la mañana. No hay así objetificación y, consiguientemente, no hay sugerencia de un ítem amorfo correspondiente a nuestro tiempo. Aunque Whorf no examina en esa sección el comportamiento semántico de la palabra día en las SAE y en hopi, no cabe duda de que también la tendría que considerar un término de fase pues, como él subraya, presenta la característica de la «ciclicidad»y, como tal, tiene los rasgos de un nombre individual, esto es, contable. Por analogía con sus observaciones sobre el uso de un término como verano en las SAE y en hopi, tendría que resultar que en hopi no se diría algo como este día, sino más bien día ahora o día recientemente, sintagmas no utilizables como sujetos o como objetos, de modo que también en este caso se evitaría la objetificación de esa fase cíclica.

En suma, Whorf conoció y empleó la distinción contable/de masa, señaló que en hopi no hay nombres de masa sino que todos son contables y afirmó que en esa lengua los nombres de ciclos temporales no admiten plurales ni cardinales - no se usaría diez días- sino solo ordinales -décimo día-. ¿Podemos pensar entonces que tal vez lo que de modo confuso quiso decir es que dia no es en hopi un nombre contable sino un nombre de masa? No hay duda de que lo que aseveró explícitamente, como acabamos de ver, es que en hopi ningún nombre es de masa. Así que no pudo querer decir eso. Además, aunque no empleó día en los ejemplos que dio de nombres de fase, podemos inferir analógicamente que, de haberlo empleado, habría dicho que el equivalente en hopi a nuestro nombre de fase dia ni siquiera es un nombre, sino que es un tipo de adverbio peculiar. Y, desde luego, sea como fuere, nada de esto eximiría a Whorf de las incoherencias que presenta su análisis de la noción de lo experienciado objetivamente.

\subsubsection{Razonamiento circular}

Podría pensarse que, de no haber sido Whorf el lamentable filósofo amateur que fue, el relativismo fuerte que defendió podría ser perfectamente respetable desde un punto de vista conceptual. Sin embargo, las objeciones anteriores no son las más importantes, las principales quedan aún por venir. La primera tiene que ver con la forma en que Whorf argumenta. En efecto, cualquier forma de relativismo lingüístico, no solo la variedad fuerte de Sapir y de Whorf, es susceptible de una objeción de circularidad y solo puede sortearla ofreciendo pruebas no específicamente lingüísticas de la contribución de las estructuras lingüísticas al pensamiento. En el caso de Whorf se ha objetado que no proporcionó 
pruebas directas de cómo piensan los hopi, sino que razonó circularmente; p. ej., que razonó circularmente que los hopi no conciben el tiempo como nosotros porque no hablan de él como nosotros (cf., p. ej., Lenneberg 1951). La TRC predice que las estructuras gramaticales del hopi determinarán una concepción del tiempo distinta de la nuestra, pero Whorf ofrece mayoritariamente como indicios empíricos de la validez de esa predicción hechos tales como que los hopi cuentan el tiempo con ordinales y no con cardinales o que no dirían una extensión de tiempo, etc. Es decir, para sostener su idea de que los hopi tienen una concepción del tiempo totalmente distinta de la nuestra no suele citar por lo general conductas no verbales, sino pautas lingüísticas distintivas. Este es un procedimiento circular que no puede probar que cuando dos lenguajes difieren en sus estructuras lingüísticas determinan visiones del mundo distintas.

Sin embargo, en el artículo citado Whorf pretende ir más allá. Sostiene que la manera en que la lengua hopi trata la pluralidad no solo determina rasgos peculiares de cómo conciben los hopi las secuencias cíclicas, sino que también tiene repercusión en cómo actúan los hopi, en ciertas pautas de conducta culturalmente distintivas: en su énfasis en la preparación y en la persistencia, en la institución del Jefe Gritador, un oficial encargado de la publicidad, etc. Así, los efectos no lingüísticos de las estructuras lingüísticas se encontrarían tanto en el pensamiento como en el comportamiento. ¿No tenemos ahí indicios que apoyan de modo inequívocamente no circular su hipótesis de que los hopi conciben el tiempo de manera peculiarmente exótica? Esa conclusión sería demasiado precipitada. En la sección final de su artículo de 1941 Whorf se pregunta: «¿Qué fue primero: las pautas lingüísticas o las normas culturales?» (Carroll 1956, p. 156). Reconoce que se desarrollaron juntas influyéndose mutuamente. Si es así, el relativismo lingüístico no puede ser confirmado mostrando sus supuestas huellas en pautas de conducta culturalmente específicas, pues la dirección de la flecha causal podría ser la inversa -tal vez esas pautas lingüísticas concretas se desarrollaran como resultado de esas normas culturales- o podría haber una relación de influencia mutua y no una relación de determinación que vaya de pautas lingüísticas a pautas de conducta cultural.

No obstante, Whorf afirma que en la asociación de pautas lingüística y normas culturales «la naturaleza del lenguaje es el factor que limita la plasticidad y rigidifica canales de desarrollo del modo más autocrático. Esto es así porque un lenguaje es un sistema, no meramente una colección de normas» (Carroll 1956, p. 156). Dado que el lenguaje presenta las características de vastedad y sistematicidad, solo puede transformarse en algo nuevo lentamente, mientras que otras innovaciones culturales se hacen con relativa mayor rapidez. Pero, significativamente, acaba concluyendo: «Hay conexiones pero no correlaciones o corres- 
pondencias diagnósticas entre normas culturales y pautas lingüísticas. Aunque sería imposible inferir la existencia de Jefes Gritadores de la carencia de tiempos en hopi, o viceversa, hay una relación entre un lenguaje y el resto de la cultura de la sociedad que lo usa» (Carroll 1956, p. 159). Pero con esta confesión Whorf está reconociendo que no puede argumentar de modo no circular a favor de su hipótesis. Si es imposible establecer la flecha causal en la dirección que va de pautas lingüísticas a conductas culturalmente determinadas, estas conductas no pueden servir como confirmación de la hipótesis de que lenguajes que difieren en sus estructuras lingüísticas determinan pautas culturales distintas.

\subsection{El problema de la «calibración» y «el efecto Ismael»}

Cualquier variedad de relativismo lingüístico tiene que ofrecer una solución a un problema del que Whorf fue consciente y para el que empleó el término «calibración»: «Para comparar los modos en que diferentes lenguas segmentan diferentemente la misma situación o experiencia, es deseable ser capaces de analizar o segmentar primero la experiencia de un modo independiente de cualquier lengua o stock lingüístico, de un modo que sea el mismo para todos los observadores» (en Carroll 1956, p. 162, con cursivas añadidas; y véase en la nota 6 la formulación canónica por parte de Whorf de su tesis cardinal, en la que le da a la noción de observación un papel central). Aquí se queda corto: no es deseable, es requerido. Parece, sin embargo, que en esta empresa el relativismo lingüístico fuerte está abocado al fracaso: si admitimos TRC -que incluye la afirmación central de que las estructuras gramaticales de lenguas diversas llevan a sus hablantes a observaciones no equivalentes-, y si subscribimos también las restantes tesis distintivas, TDL, TRM y TI, ¿qué base resta para la comparación neutral de categorías lingüísticas y para la formulación de generalizaciones legales interlingüísticas? Si solo podemos acceder al mundo a través de las categoría que nos impone nuestra lengua y resulta que lenguas diversas imponen tiránicamente concepciones del mundo incomensurables, ¿cómo podríamos librarnos de esas cadenas para ver y segmentar el mundo de modo lingüísticamente inocente? ¿Dónde podríamos encontrar puntos fijos para el calibrado?

Whorf intentó solucionar, inconsistentemente, el problema de la calibración buscando puntos de anclaje en fenómenos no lingüísticos, en una «experiencia tal como debe ser para todos los seres humanos, independientemente de sus lenguas o filosofías» (en Carroll 1956, p. 6). Pensó en algún momento que esa base no lingüística podría encontrarse en las leyes universales de la percepción postuladas por los psicólogos gestaltistas. Sin embargo, el hecho de que presumiblemente esas leyes 
serían en principio extensibles a la especie humana parece estar en tensión con la idea de la función del lenguaje como conformador de la percepción, no solo de la conceptualización, que es parte integrante de TRC $^{5}$. Por otro lado, con su insistencia en la parroquialidad de las categorías y leyes de la ciencia y de la lógica -una suerte de relativismo posmoderno avant la lettre- Whorf también cerró las puertas a la posibilidad de que la calibración pudiera venir por esas vías.

También ensayó una solución por un camino lingüístico: construir lo que Lucy llama un «metalenguaje neutral», un marco de comparación que fuese el resultado de un estudio contrastivo de las diversas lenguas. ¿Pero de dónde podrían provenir los términos de ese pretendido metalenguaje «neutral»? Pues Whorf insistió en que las categorías gramaticales con las que analizamos las SAEs son también parroquiales, son «criaturas de las lenguas indoeuropeas y de sus jergas subsidiarias, y reflejan los modos típicos de segmentar la experiencia en esas lenguas» (en Carroll 1956, p. 162). Así pues, resulta necesario acuñar categorías nuevas.

Al encarar este problema, Lucy sostiene que «Whorf implementó un método comparativo que usa la realidad constituida por [el inglés y el hopi] como un metalenguaje neutral para la descripción del significado de cada uno de ellos» (1992a, p. 266). ¿Pero qué sentido literal puede tener hablar de la realidad como de un metalenguaje? La realidad no es ningún tipo de lenguaje objeto ni de metalenguaje que pueda utilizarse para describir nada; es algo que debe ser ello mismo descrito en algún lenguaje. Y si lenguajes diversos condicionan modos incomensurables de describirla, no hay calibración posible. Lucy parece advertir su desliz cuando unas páginas después habla, ya no de la realidad como metalenguaje descriptivo, sino de la necesidad de «una descripción neutral de la realidad para los propósitos de la comparación, esto es, una descripción que no privilegie las categorías de un lenguaje o cultura cualesquiera desde el inicio» (ibid., p. 273), y sostiene que «la realidad puede ser descrita tal como aparece a través de la ventana del lenguaje» (ibid., p. 275). Esto último ya tiene sentido y tal vez sea factible, pero apunta a una vía que le está vedada al whorfianismo fuerte: si la realidad solo puede ser abordada tal como se ve «a través de la ventana» del lenguaje y si lenguas diversas imponen visiones de la realidad diversas

\footnotetext{
${ }^{5}$ Lucy 1992a, pp. 41-43 señala, tal vez con justicia, que Whorf estaba interesado primariamente en los conceptos y no en los perceptos. Sin embargo, no hay que perder de vista que en diversas ocasiones Whorf subscribe la tesis de la función del lenguaje como «conformador de la percepción». He aquí como enuncia su doctrina central, que denomina «el principio de relatividad lingüística»: «usuarios de gramáticas marcadamente diferentes son dirigidos por las gramáticas hacia diferentes tipos de observaciones y diferentes evaluaciones de actos de observación externamente similares, y por ello no son equivalentes como observadores sino que deben llegar a visiones del mundo de alguna manera diferentes» (en Carroll 1956, p. 221; cursivas añadidas).
} 
e incomensurables, no queda espacio para un metalenguaje neutral. En cambio, a un relativista conceptual de raigambre kantiana, por ejemplo, sí que le quedaría abierto ese espacio, puesto que afirmaría la universalidad de las categorías.

En pocas palabras, da la impresión de que el intento por parte de Whorf de tocar las campanas del relativismo fuerte e ir a la procesión de la descripción neutral es una muestra de lo que el filósofo australiano David Stove llamó ingeniosamente «el efecto Ismael» ${ }^{6}$. Aplicándolo al caso de Sapir y Whorf, ellos tuvieron éxito en librarse de las cadenas irrompibles del lenguaje, de manera que estuvieron en situación de informarnos a los demás de que nadie puede librarse de las cadenas irrompibles del lenguaje.

A menudo, Whorf tiende a exponer la relación lenguaje-pensamiento-realidad en términos que recuerdan un idealismo kantiano lingualizado: «el mundo es un flujo caleidoscópico de impresiones que ha de ser organizado por nuestras mentes -y esto significa en gran medida por el sistema lingüístico de nuestras mentes» (en Carroll 1959, p. 213). He aquí otro pasaje del mismo tenor: «el mundo vastísimo, desconocido -ese mundo del que lo físico no es sino una superficie o piel, y no obstante ESTAMOS EN y PERTENECEMOS A él» (Carroll 1956, p. 248). Whorf usa también la metáfora schopenhaueriana del «microcosmos que cada hombre lleva dentro de sí» (en Carroll 1956, p. 147), un «microcosmos lingüísticamente condicionado» (Carroll 1956, p. 148). (Ignoro si Whorf había leído a Schopenhauer o sobre él.) Estos pasajes parecen implicar que sí existe una única realidad, pero que, como la cosa en sí kantiana o la voluntad schopenhaueriana, no podemos acceder a sus características; tan solo alcanzamos aquello a lo que imponemos nuestras propias categorías. En cambio, como ya hemos visto, encontramos ocasionalmente pasajes que parecen sugerir que, al igual que Sapir, cuya afirmación es explícita, Whorf se compromete con TRM, con la idea de que no hay un único mundo desconocido en el que estamos, sino que hablantes de lenguas diversas viven en mundos diferentes: «los hechos son diferentes para hablantes cuyo trasfondo lingüístico les proporciona una forma diferente de formularlos» (en Carroll 1956, p. 235). Tal vez Whorf, como el penoso filósofo amateur que era, no se percató de esta incongruencia entre TRM y la idea de un único mundo, vasto y desconocido. Se suele decir que no hay peor cosa que un científico metido a filósofo a tiempo parcial; la hay: un científico a tiempo parcial metido a filósofo amateur. Desde la perspectiva de un idealismo transcendental de cuño kantiano, las categorías que imponemos a la reali-

\footnotetext{
${ }^{6}$ En Stove 1991. Efecto «Ismael» en honor de Ismael, el personaje del que se sirve como narrador Herman Melville en la novela Moby-Dick, aquel personaje que afirma que, habiendo perecido todos en el naufragio, él sobrevivió para contarnos la historia.
} 
dad serían universales y proporcionarían por ello puntos fijos para la calibración. Por el contrario, una vez que el kantismo es lingualizado y relativizado, ya no puede haber coordenadas comunes.

\subsection{El whorfianismo fuerte no es susceptible de control empírico}

A diferencia del español o de otras lenguas indoeuropeas, en turco -y en ciertas lenguas amerindias- hay una distinción evidencial de aspecto en los tiempos pasados, de modo que le es obligatorio al hablante seleccionar entre una de dos inflexiones del pasado dependiendo de si ha sido testigo del suceso que narra o solo lo ha conocido por inferencia o de segunda mano. No es posible decir algo equivalente al simple llovió anoche. Un hablante que haya presenciado directamente la lluvia que cayó anoche debe utilizar el pasado evidencial para dar cuenta de ese suceso (algo así como ayer + llover + PASADO.PRESENCIADO); un hablante que se haya enterado de la lluvia de anoche por testimonio o que se levante por la mañana y advierta que las calles están mojadas está obligado a usar el pasado no evidencial (algo así como ayer + llover + PASADO.NO-PRESENCIADO).

Si tomamos en serio la posición del whorfiano fuerte, tendría que ser posible en principio mostrar que los turcos son más sensibles a la experiencia directa que los anglohablantes o los hispanohablantes, pero que estos últimos son más conscientes de la muerte que los turcos. Y es claro que una hipótesis tan ambiciosa, a tan gran escala, no puede ser confirmada ni refutada empíricamente, entre otras cosas porque el pensamiento y la acción humanos son sobredeterminados por una panoplia de causas y pudiera ser que el lenguaje no fuese el factor predominante. La moraleja es que el whorfianismo fuerte no es empíricamente controlable.

\section{EL RESURGIMIENTO CONTEMPORÁNEO DEL RELATIVISMO LINGÜÍSTICO}

En parte, lo que le confiere al whorfianismo clásico su carácter fuerte, lo hace conceptualmente implausible y lo convierte en no susceptible de control empírico es cómo entiende la relación de influencia y los dos términos entre los que se da. La influencia la representa como una suerte de coerción; de ahí la proposición TDL. En cuanto al primer término de la relación, Whorf tiende a concebir el lenguaje holísticamente a la manera en que Saussure y otros estructuralistas lo concibieron. De ahí que haga hincapié en pautas gramaticales más que en ítems léxicos, pues es más probable que las primeras repercutan globalizadamente en el sistema de la lengua, y también que haga hincapié, no en 
ciertas pautas particulares, sino en formas de hablar que se interpenetran y se determinan sistemáticamente. El segundo término de la relación es también para Whorf una totalidad sistemática, una visión o concepción global del mundo - una world-view, como él la denomina.

La hipótesis de Sapir-Whorf gozó de popularidad en amplios círculos en los años 50 y 60 del siglo pasado. Aunque en la estela de Whorf continuó habiendo una interesante serie de trabajos empíricos llevados a cabo por antropólogos y psicolingüistas ${ }^{7}$, el whorfianismo cayó en descrédito, como antes señalé, cuando se impuso una nueva sensibilidad con el auge del paradigma nativista y cognitivista que va asociado con las tesis chomskyanas y fodorianas acerca del carácter innato, universal y modular de las estructuras lingüísticas básicas.

Formas más suaves de relativismo lingüístico podrían resultar de debilitar la naturaleza de la relación o de acotar el alcance de uno u otro de sus términos. El relativismo lingüístico que viene resurgiendo desde finales de siglo pasado se centra en formas de influencia no coercitivas o en «efectos whorfianos» más limitados y susceptibles de control empírico. Atenderé a tres ámbitos en los que los whorfianos de los últimos días han postulado efectos del lenguaje sobre el pensamiento:

(1) el dominio de los sucesos de movimiento,

(2) el de la localización espacial, y

(3) el de la forma y la composición material de los objetos.

Dedicaré más espacio al primero, en conexión con la hipótesis de Slobin del "pensar para hablar», ya que esa hipótesis constituye la forma más suave de neowhorfianismo y, por ello, en caso de estar justificada, la más soportable desde una perspectiva universalista.

\subsection{Sucesos de movimiento: la hipótesis de Slobin del «pensar para hablar»}

4.1.1. La hipótesis del «pensar para hablar»: efectos whorfianos en el lenguaje en uso

La obra de Dan Slobin ${ }^{8}$ constituye una buena ilustración del abismo que separa las ambiciones del whorfismo fuerte clásico y el carácter más comedido de algunas investigaciones recientes. Slobin rechaza la forma inmodesta de relativismo que propusieron Sapir y Whorf, pero cree defendible una variedad más morigerada, descendiente de Boas,

\footnotetext{
${ }^{7}$ Un detallado examen de esos estudios puede hallarse en Lucy 1992a, caps. 3-7; véase también Lucy 1997.

${ }^{8}$ Véanse los trabajos de Slobin consignados en la bibliografía de este artículo.
} 
que llama «la hipótesis del pensar para hablar». Por «pensar para hablar» entiende los procesos mentales que ocurren durante el acto de formular una proferencia; es decir, el pensar que es llevado a cabo on-line en el proceso de hablar. El suyo es, pues, un enfoque dinámico, centrado en el lenguaje en uso, en el discurso, y no en una entidad estática, el lenguaje entendido como sistema. Como revela el título de uno de sus artículos más pertinentes (Slobin 1996b), lo que pretende es substituir la perspectiva whorfiana canónica, focalizada en la relación entre dos entidades estáticas, el lenguaje y el pensamiento (o mejor, la concepción del mundo), por una perspectiva distinta que pone el foco de atención en la relación entre dos actividades, dos entidades dinámicas, el pensar y el hablar. Escribe Slobin (1996b, p. 435):

La actividad de pensar adquiere una cualidad particular cuando es empleada en la actividad de hablar. En el marco temporal evanescente de construir proferencias en el discurso, cada uno encaja sus pensamientos en formas lingüísticas disponibles. Una proferencia particular nunca es un reflejo directo de la realidad objetiva o percibida, o de una representación mental inevitable y universal de una situación. Esto es evidente dentro de cada lengua dada, porque la misma situación puede describirse de diferentes maneras, y es evidente interlingüísticamente, porque cada lengua proporciona un conjunto de opciones limitado para la codificación gramatical de las características de los objetos y los sucesos. «Pensar para hablar» comporta seleccionar aquellas características que (a) encajan en alguna conceptualización del suceso y (b) son fácilmente codificables en la lengua.

La hipótesis de Slobin es que el lenguaje influye en el pensamiento cuando se está «pensando para hablar», esto es, cuando se está pensando «con el propósito de usar el lenguaje». Un detractor del whorfianismo tan virulento como Steven Pinker había admitido una cierta forma de esta hipótesis: «Whorf estaba ciertamente equivocado cuando dijo que el lenguaje de cada uno determina cómo conceptualiza la realidad en general. Pero probablemente estaba en lo correcto en un sentido mucho más débil: el lenguaje de cada uno determina cómo debe conceptualizar la realidad cuando tiene que hablar de ella» (1989, p. 360). Sin embargo, este reconocimiento solo deja espacio para una influencia que no se extiende más allá de algo muy restringido: el momento en el que el hablante tiene que expresar sus pensamientos con palabras. En particular, Pinker piensa que no hay indicios científicos que apoyen una tesis interesante según la cual el lenguaje tenga una función conformadora del pensamiento: «es altamente improbable que los holandeses conciban [los significados subyacentes asociados a construcciones verbales] de modo diferente que nosotros, excepto en el momento en que tienen que expresarlos con palabras» (Pinker 1989, p. 358). Es decir, contra TRC, los efectos del pensar para hablar no comportan implicaciones para la percepción o la conceptualización de la realidad. 
La hipótesis de Slobin va más allá porque sostiene que esta influencia no es trivial, sino que lleva a los hablantes a prestar atención diferencial a ciertos rasgos de la experiencia cuando hablan de ella. En particular, Slobin propone que el lenguaje en uso tiene efectos no lingüísticos, efectos cognitivos; concretamente, tiene efectos en la atención selectiva y en la memoria. Esos efectos se producen tanto en el momento en el que el usuario del lenguaje tiene que expresar sus pensamientos con palabras, cuando desempeña el papel de hablante, como en el momento en el que tiene que escuchar para entender o traducir, cuando ocupa el lugar de la audiencia, entendida en sentido amplio:

solo podemos hablar y entendernos mutuamente en términos de una lengua particular. La lengua o lenguas que aprendemos en la niñez no son sistemas de codificación neutral de una realidad objetiva. Por el contrario, cada una es una orientación subjetiva al mundo de la experiencia humana y esa orientación afecta a las maneras en que pensamos mientras estamos hablando (Slobin 1996b, p. 91).

el estudio serio del lenguaje en uso apunta a efectos de alta difusión del lenguaje sobre la atención selectiva y el recuerdo respecto de características particulares de los sucesos... sean cuales fueren los efectos que pueda tener el lenguaje cuando las personas no están hablando o escuchando, la actividad mental que acontece mientras se formulan e interpretan proferencias no es trivial u obvia y merece nuestra atención (Slobin 2003, p. 159).

Mientras que el whorfianismo clásico atendía a vastas diferencias estructurales entre las lenguas y buscaba efectos cognitivos o comportamentales de amplio espectro, Slobin delimita más cautamente los dos términos de la relación de influencia propugnando una metodología que presenta dos características:

(a) se concentra en aquellas partes de las proferencias que resultan obligatorias en virtud de la organización gramatical de la lengua, $y$

(b) se concentra en situaciones en las que el lenguaje es el principal medio de llamar la atención de las personas hacia un aspecto particular de la experiencia.

\subsubsection{Un experimento mental: los pronombres de distancia y respeto}

Una ilustración que propone Slobin es la siguiente. Cuando en español -o en francés o en alemán- nos dirigimos a un interlocutor mediante un pronombre personal, es obligatorio que seleccionemos un pronombre de distancia o respeto (usted) o un pronombre de confianza o superioridad (tú); en cambio, en inglés hay un solo pronombre de segunda persona (you), de modo que a un anglohablante ni se le ofrece 
ni se le exige ese tipo de opción ${ }^{9}$. Por tanto, quienes hablan una lengua en la que se debe seleccionar una forma de pronombre que marca la relación social del hablante con el interlocutor deben categorizar a cada persona a la que se dirigen con un pronombre en términos de las dimensiones relevantes (persona socialmente distante o de respeto $v$ s. persona cercana o inferior socialmente).

Desde una posición whorfiana, incluso débilmente whorfiana, debería ser posible en principio mostrar que esas diferencias lingüísticas imponen en los hablantes efectos no lingüísticos, cognitivos o comportamentales. Con respecto al sistema de pronombres de segunda persona del español, Slobin nos sugiere un experimento mental de determinismo lingüístico: imagínense las categorizaciones de las relaciones sociales que tendrían que hacerse si la balanza política cambiase en los Estados Unidos y el español se convirtiera en la lengua oficial.

En mi opinión, es un mal experimento mental. En primer lugar, en inglés hay posibilidades de bypass, de modo que el hablante suele marcar su relación social con su interlocutor utilizando medios léxicos alternativos. Por ejemplo, si el hablante se dirige a su interlocutor empleando su nombre propio estará indicando que lo considera persona de confianza o tal vez socialmente inferior; si su relación con él es de distancia o respeto, utilizará el apelativo Sir o se dirigirá a él por su apellido precedido de honoríficos como $M r, M s$, Professor, Doctor, etc. Así pues, ausencia de obligatoriedad de opción en cuanto al pronombre personal de segunda persona no implica ausencia de categorización social. Nadie más consciente de las diferencias sociales que los ingleses -o quizás mejor, que los ingleses de hace algunas décadas-. El propio Slobin reconoce la fuerza de esta consideración cuando advierte «tenemos de hecho medios léxicos opcionales para expresar nociones que caen fuera del conjunto de las distinciones gramaticales que son obligatorias en una lengua» (1996b, p. 74). Por tomar el ejemplo anterior de las inflexiones evidenciales del pasado en turco, tenemos a nuestra disposición recursos léxicos opcionales para expresar lo que en turco se expresa con el pasado no evidencial: podemos decir algo así como por lo visto, anoche llovió. Pero si disponemos de tales recursos opcionales, debemos excluir del estudio un dominio que los contenga, so pena de que ya no sea respetado el rasgo (a) de la metodología propugnada por Slobin -concentrarse en aquellas partes de las proferencias que resultan obligatorias en virtud de la organización gramatical de la lengua.

En segundo lugar, las diferencias de preferencia con respecto a los pronombres personales de distancia y respeto son a menudo meramen-

\footnotetext{
${ }^{9}$ Se cuenta una divertida anécdota acerca de Helmut Kohl, cuyo inglés era también «very bad». Cuando visitó por vez primera al presidente George Bush padre se presentó diciéndole: I am Helmut Kohl and you can say me you.
} 
te pragmáticas. Pensemos en cómo ha cambiado el respeto si comparamos la España actual, donde se recurre rápidamente al tuteo, con la España de hace unas décadas. Y no solo las diferencias se dan con el paso del tiempo. Pues pensemos también en las diferencias existentes entre el español actual de España, en el que el uso de los pronombres de distancia y respeto cada vez es menos frecuente, con el español actual de Hispanoamérica, donde siguen muy vivos no solo esos pronombres, sino también otros marcadores de respeto como los títulos honoríficos. Nadie se dirige actualmente a otro en España con el venerable título $\mathrm{Li}$ cenciado (por obra y gracia del Espacio Común Europeo de Educación, los licenciados somos una especie en extinción) ${ }^{10}$.

Finalmente, tomemos el caso de los pronombres demostrativos. Mediante ellos podemos situar los objetos del discurso en términos de su distancia al ego. El español y el inglés tratan este tipo de distalidad de maneras diferentes. En español el sistema de pronombres demostrativos es tripartito: en el género neutro tenemos esto (distancia corta), eso (distancia media) y aquello (distancia larga). En inglés, no solo no hay diferencia de género, sino que el sistema es bipartito: this (distancia corta), that (distancia larga). ¿Tendríamos que concluir whorfianamente que españoles e ingleses percibimos la distancia al ego de modo diferente o, tal vez peor, que tenemos diferentes conceptos de distancia? Hay una respuesta alternativa que resulta más plausible y con la que podría mostrarse de acuerdo un antirrelativista como Pinker: que para los propósitos de la expresión codificamos léxicamente la distalidad de modo diferente pero la percibimos de modo uniforme, de un modo condicionado por el aparato perceptivo general y específico de nuestra especie.

\subsubsection{Un estudio empírico: las descripciones de los sucesos de movimiento}

Slobin reconoce que el caso de los pronombres de distancia y respeto no pasa de ser un mero experimento mental. No obstante, cree que su hipótesis es susceptible de ser confirmada con investigaciones empíricas controladas y ofrece estudios concretos para apoyarla. Son especialmente interesantes los que tienen que ver con las descripciones de los sucesos de movimiento.

Hay una notable diversidad interlingüística en las pautas de lexicalización de esos sucesos. Talmy 1985, 1991, 2000 desarrolló una sistematización de los componentes básicos de un suceso de movimiento.

\footnotetext{
${ }^{10}$ El propio Slobin cita el trabajo de Brown y Gilman 1960, en el que se muestra cómo los criterios para elegir en francés entre el pronombre $t u$ y el pronombre vous han variado históricamente y varían también de unos a otros países europeos.
} 
Además de la presencia misma del movimiento (un cambio de localización), de la FIGURA (el objeto en movimiento) y del FONDO (el objeto que se toma como punto de referencia con respecto al cual se mueve la figura), dos componentes básicos son la TRAYECTORIA (el curso que sigue la figura con respecto al fondo) y la MANERA del movimiento (el modo en que se mueve la figura). Esos cinco ingredientes se muestran entre paréntesis y en cursivas en la siguiente oración: el pájaro (FIGURA) fue (MOVIMIENTO) hacia (TRAYECTORIA) la jaula (FONDO) volando (MANERA). Talmy señaló que las lenguas tienden a lexicalizar la trayectoria de una de dos formas: las llamadas lenguas-V, como el español, lo hacen en el verbo (p. ej., entrar, salir, subir, bajar); las lenguas-S, como el inglés, lo hacen en una partícula asociada o «satélite» (p. ej., go into, go out, go up, go down). Esa diferencia tipológica es ejemplificada por el contraste entre la oración española el pájaro entró en la jaula y su versión inglesa the bird went into the jail. En los lenguajes-S, como el inglés, la manera es altamente codificable porque es indicada por el verbo principal. En las lenguas- $\mathrm{V}$, como el español o el francés, la manera suele indicarse con un adjunto y a menudo queda sin mencionar. Es la diferencia ejemplificada por the bird flew into the jail frente a el pájaro entró en la jaula volan$d o$. En otras palabras, las lenguas-S tienden a conglomerar en el verbo la trayectoria y la manera, y por ello son más propicias a lexicalizar la manera; las lenguas-V separan la codificación léxica de la trayectoria y de la manera, y por ello se prestan más a omitir la manera.

Slobin defiende que estas diferencias en pautas de lexicalización producen tanto efectos lingüísticos como efectos cognitivos. Por lo que hace a los primeros, el hecho de que las lenguas-V, a diferencia de las lenguas-S, proporcionen recursos finos, habituales y económicos para codificar la manera del movimiento produce diferencias en el modo en que los hispanohablantes y los anglohablantes describen los sucesos de movimiento. Así, sucederá que comparativamente en las lenguas-V, como el inglés,

(a) aparecerán más frecuentemente referencias a la manera del movimiento en cualquier tipo de género o de contexto de discurso;

(b) la adquisición de los verbos de manera se producirá primero;

(c) esas lenguas presentarán una constante innovación léxica en este dominio, incluyendo usos extendidos y metafóricos.

En cuanto a (a), Slobin señala que las lenguas- $V$ tienden a tener menos verbos de movimiento que las lenguas-S; p. ej., el verbo español escabullirse admite en inglés las traducciones creep, glide, slide, slip y slither. Correlativamente, los verbos de manera aparecen menos frecuentemente en el discurso en las lenguas-V. Para establecer (b) no basta con aducir, como hace Slobin, datos estadísticos que muestran que los ni- 
ños que están aprendiendo lenguas-S emplean un léxico que contiene un mayor número de esos verbos. Eso no tendría por qué ser en sí mismo asombroso si las lenguas-V tienen más verbos de manera que las lenguas-S. Lo que debería mostrarse es que los aprendices de lenguas-S adquieren los verbos de manera de su lengua a una edad más temprana que aquella en que los aprendices de lenguas-S adquieren los verbos de manera de la suya. Como prueba de (c), Slobin apunta que en la historia del inglés se observa una continua adición de nuevos verbos de manera -veintitrés verbos intransitivos fueron innovados en el siglo XIX, según el $O E D-$ y que en inglés es más frecuente que en las lenguas-V el uso de verbos de manera para describir sucesos políticos y económicos, como también lo es el uso metafórico de esos verbos en obras de ficción. A este respecto, hace sugerentes análisis estilísticos de pasajes de novelas en español; sugerentes, si bien discutibles, pero este no es un asunto en el que demorarse ahora.

No obstante, me parece que admitir las anteriores tres clases de efectos no es incompatible con aferrarse a una posición como la de Pinker, quien, como hemos visto, da limitadamente la razón a Whorf en que «el lenguaje de cada uno determina cómo debe conceptualizar la realidad cuando tiene que hablar de ella» (cursivas mías), pero que descree de la grandiosa pretensión whorfiana de que las diversas formas de codificar lingüísticamente la realidad tienen efectos en la percepción o en la conceptualización de la realidad misma. Pues, pese a la falta de claridad de Slobin sobre el asunto, los efectos de los tipos (a)-(c) son específicamente lingüísticos; son perceptibles en cómo los usuarios de lenguajes tipológicamente diversos «describen» obligatoria o habitualmente los sucesos de movimiento, o en cómo, en su calidad de oyentes o lectores, «descodifican» las descripciones lingüísticas que se encuentran.

Pero Slobin no se queda ahí sino que postula también efectos específicamente cognitivos, ya no meramente lingüísticos. A saber, sucederá también que comparativamente en las lenguas-V, como el inglés,

(d) los hablantes tendrán una rica imaginería mental de la manera del movimiento; y

(e) la manera del movimiento será prominente en la memoria cuando los hablantes recuerden o registren verbalmente sus recuerdos de los sucesos de movimiento.

Ya no se trataría de efectos confinados al lenguaje sino de efectos del lenguaje en uso sobre dos aspectos de la cognición de los usuarios: sobre su imaginación y sobre su memoria. Dada esa diferencia entre los pretendidos efectos de los tipos (a)-(c) y los de los tipos (d)-(e), si pudiera establecerse fehacientemente que se dan efectos de esta última índole, un whorfianismo atemperado como el que propone Slobin que- 
daría vindicado: habría efectos whorfianos en el «pensar para hablar»; más concretamente, los habría en el imaginar y en el recordar mientras hablamos o comprendemos el discurso.

Por limitarnos a (d), en lo tocante a la imaginación, Slobin llama la atención hacia la investigación experimental de los efectos conceptuales del lenguaje en el curso de la recepción del discurso. Los usuarios de las lenguas-S están más sometidos a descripciones más finas y elaboradas de la manera de los sucesos de movimiento y, con respecto a los sucesos descritos, su imaginería mental -en comparación con la de los usuarios de lenguas-V- es más rica: contiene más información sobre la manera, incluyendo las conclusiones valorativas extraíbles de esa información.

\subsubsection{Gennari y otros vs. Slobin}

Silvia Gennari y sus asociados investigaron si las diferencias en el modo en que hispanohablantes y anglohablantes codifican lingüísticamente los sucesos de movimiento repercuten en sus representaciones no lingüísticas de esos sucesos (Gennari, Sloman, Melt y Fitch 2002; Melt, Sloman y Gennari 2003). Propusieron a los sujetos de su experimento tres tareas cognitivas, una que tenía que ver con la descripción de los sucesos, otra con la memoria de reconocimiento y otra con juicios de semejanza. En esas tareas se les mostraban vídeos de sucesos de movimiento. En unos la manera del movimiento cambiaba mientras que la trayectoria seguía siendo la misma; en otros, la trayectoria se alteraba mientras que la manera se mantenía constante. Sus hallazgos fueron los siguientes:

(a) En la tarea de descripción hubo diferencias interlingüísticas en el modo en que los sujetos codificaban los sucesos: los anglohablantes tendían a usar el mismo verbo para acciones que compartían la manera, mientras que los hispanohablantes tendían a asignar el mismo verbo a acciones que compartían la trayectoria.

(b) En la tarea de reconocimiento no hubo diferencias entre ambos grupos, excepto cuando el sujeto había dado previamente una etiqueta lingüística al suceso en el momento de percibirlo.

(c) En la tarea de semejanza no hubo diferencias, excepto cuando, en el caso del español, el participante había codificado previamente el suceso lingüísticamente o, en el caso del inglés, se daban «condiciones de obscurecimiento».

Son importantes los hallazgos (b) y (c), pues (a), aunque interesante porque confirma que cada lengua tiene una pauta preferida de descripción que es consistente con la tipología de Talmy, es un resulta- 
do que tiene que ver con las representaciones lingüísticas. A ese respecto no difiere de los resultados (a)-(c) que Slobin encontraba y sigue siendo compatible con las cautelas expresadas por Pinker. Por el contrario, los resultados (b) y (c) entran en conflicto con la pretensión de Slobin de que el lenguaje en uso tiene efectos cognitivos, efectos en las representaciones no lingüísticas. Por ejemplo, Gennari y sus colegas encontraron que los hispanohablantes no exhibían una preferencia mayor por las opciones misma-trayectoria que los anglohablantes, es decir, no mostraban la pauta de respuesta predicha por sus sesgos lingüísticos -por el hecho de que los anglohablantes tienden a codificar tanto la manera (en el verbo) como la trayectoria (en una expresión adverbial), mientras que los hispanohablantes típicamente codifican la trayectoria en el verbo y tienden a omitir la manera. En suma, la pauta que hallaron no se compadece con la tesis whorfiana que postula que el lenguaje tiene una influencia obligatoria o habitual en el procesamiento no lingüístico.

No obstante, hay que prestar atención a las cláusulas que aparecen en (b) y en (c). En cuanto a (b), el resultado que obtuvieron Gennari y sus colegas es que las diferencias lingüísticas en el modo en que anglohablantes e hispanohablantes codifican aspectos del movimiento no influyen en su memoria de reconocimiento, excepto cuando las tareas admitian que los sujetos etiquetasen las entidades a recordar, de modo que esas etiquetas actuasen como pistas de recuperación para la realización de las tareas. Por lo que hace a (c), tampoco hallaron influencias en los juicios de semejanza que hacían los agentes, excepto cuando, en el caso del español, intervenian etiquetas lingüisticas en la tarea y, en el caso del inglés, se daban «shadow conditions», concretamente, cuando los sujetos eran obligados a pronunciar sonidos sin sentido durante la tarea. Como ellos resumen brevemente: «Hallamos un efecto lingüístico en la tarea de semejanza tras la codificación verbal, especialmente en el caso de los hispanohablantes, un efecto que se conformaba con las pautas específicas de la lengua. También hallamos que la memoria de reconocimiento de los hablantes de ambas lenguas mejoraba con la codificación lingüística» (Melt y otros 2003, pp. 101-102). Esto apunta, comentan, a que el lenguaje puede servir como un instrumento útil en tareas de recuperación de recuerdos. Sin embargo, si de hecho los efectos whorfianos solo se dan en tareas mediadas por el lenguaje, damos una vez más con otra guisa del problema de la circularidad que ya habíamos encontrado en Whorf.

Parece, pues, que las anteriores excepciones muestran que, si bien los hallazgos de Gennari y sus asociados no son compatibles con la pretensión whorfiana de que la lengua tiene una función conformadora del pensamiento, sí lo son con una tesis mucho más débil y que ha sido subrayada por muchos: que el lenguaje tiene funciones potenciadoras o facilitadoras. La primera pretensión tiene que ver con las diferencias entre hablar una lengua particular en cuanto distinta de otras; la segunda 
tiene que ver con las diferencias entre poseer un lenguaje y no poseer ninguno. Es difícil ver cómo podría negarse que la posesión de un lenguaje aumenta o facilita nuestra capacidad de representación y de razonamiento. Empíricamente, lo interesante es investigar en qué dominios y por qué mecanismos se produce ese aumento; por ejemplo, el lenguaje puede proporcionar medios de integrar fuentes de información que no pueden ser integradas en otros sistemas representacionales. Puede también proporcionar una fuente de información que es susceptible de ser explotada en la toma de decisiones o puede ayudar a codificar información y a recuperarla de la memoria, como Gennari y sus asociados subrayan.

En suma, los hallazgos de Gennari y sus colegas tienen consecuencias negativas para el whorfianismo: las diferencias interlingüísticas producen efectos en las representación lingüística, como Pinker admitió, pero, de no estar mediadas por interferencias lingüísticas, carecen de impacto en las representaciones no lingüísticas, en contra de lo que Slobin propone.

La hipótesis de Slobin postula efectos cognitivos cuando pensamos para hablar -o escribir o entender el discurso si es que ocupamos el rol del oyente o del traductor-. Dicho de otro modo, postula efectos whorfianos en el nivel de la regimentación de los pensamientos. Así, tras insistir en que las diferencias en el modo en que lexicalizan el movimiento una lengua-S como el español y una lengua-V como el inglés tienen efectos en lo que es dicho y en lo que no es dicho en esas lenguas, y asimismo en la atención diferencial que sus usuarios prestan a los diferentes componentes de los sucesos de movimiento, Slobin se apresura a precisar: "permítaseme subrayar que estoy hablando del pensar para hablar solamente. No estoy afirmando nada acerca de cómo conciben la vida o actúan en el mundo millones de hispanohablantes y de anglohablantes» (1996b, p. 85; las cursivas son del propio autor). Aquí está distanciándose del whorfianismo fuerte; en concreto, de la tesis TRC en su forma clásica.

Formas más fuertes del whorfianismo contemporáneo postulan efectos cognitivos que no quedan confinados al lenguaje en uso, sino que se producen más allá del tiempo de hablar, que se extienden al tiempo en que son experimentadas las situaciones codificadas; esto es, postulan efectos cognitivos que se dan fuera del discurso o de la comprensión lingüística. De acuerdo con estas versiones más fuertes, ciertos procesos cognitivos no lingüísticos de los hablantes de una lengua particular van unidos estrecha, si es que no inextricablemente, a la forma y el contenido de esa lengua. Me centraré en dos estudios que parecen más representativos y convincentes: los realizados sobre localización espacial por el grupo de Nimega bajo la dirección de Stephen Levinson y los llevados a cabo por John Lucy y sus asociados sobre ciertos efectos whorfianos de las lenguas clasificadoras. 


\subsection{Marcos de referencia espacial: Brown y Levinson sobre el tzeltal}

\subsubsection{Los efectos cognitivos de los marcos de referencia espacial}

Stephen Levinson y sus asociados en el Instituto Max Planck de Psicolingüística de Nimega han sostenido que los tipos de coordenadas o marcos de referencia que incorporan las lenguas para describir la localización espacial de los objetos pueden organizarse en una tipología universal que distingue exactamente tres tipos principales, de los cuales las lenguas y las culturas extraen un subconjunto (Levinson 2003 es el libro clave; cf. también Brown y Levinson 1993 sobre el tzeltal). Nuestras lenguas familiares utilizan predominantemente un marco de referencia relativo, i. e., egocéntrico, o más estrictamente objetocéntrico (enci$\mathrm{ma} /$ debajo, a la derecha/a la izquierda, etc.) y lo suplementan con un marco intrínseco, i. e., centrado en propiedades del objeto que se toma como referente (su parte delantera/trasera, etc.). Pero en lenguas como el maya tzeltal el marco de referencia es absoluto, i. e., geocéntrico, con puntos fijos geográficos (al norte/al sur, al este/al oeste, etc.), suplementado con un sistema intrínseco. En ellas no se utiliza un marco de referencia relativo: no se diría en tzeltal el balón está a mi izquierda, sino, pongamos por caso, el balón está al norte de mí o el balón está delante del carro. En nuestras lenguas familiares también puede usarse un marco absoluto, pero solo para objetos que alcanzan un cierto tamaño (decimos Asturias está al norte de León, pero el balón está al norte de mí sonaría anómala; más bien diríamos, pongamos por caso, el balón está a mi izquierda).

Brown y Levinson sostuvieron que esas diferencias de codificación lingüística producen efectos whorfianos en el lenguaje y en la cognición, afectando al modo en que los hablantes codifican las relaciones espaciales en tareas no lingüísticas. Por citar una de poco calado, un hablante de tzeltal tiene dificultades para percibir la diferencia entre $b$ y $d$. Para confirmar su tesis, Brown y Levinson suministraron a un grupo de hablantes de holandés y a un grupo de hablantes de tzeltal una variedad de tareas de rotación que podían llevarse a cabo o bien de acuerdo con un marco absoluto o bien con un marco relativo. Una rotación de $180^{\circ}$ invierte un marco relativo (lo que estaba a la izquierda pasa a estar a la derecha) pero deja intacto un marco absoluto (el norte sigue siendo el norte y el sur sigue siendo el sur). Los sujetos veían, por ejemplo, una fila de objetos sobre una mesa que apuntaban a su izquierda, se giraban $180^{\circ}$ grados y se les pedía que desde la nueva posición colocasen la fila sobre otra mesa de modo que quedase como antes. Si apuntaban a su izquierda, la concebían en términos de coordenadas egocéntricas; si apuntaban a su derecha (p. ej., al sur), pensaban en términos de coordenadas geocéntricas. Encontraron que cada grupo lingüístico respondía a esas tareas no lingüísticas afectadas por la rota- 
ción de una manera congruente con el marco de referencia dominante en su lengua. Además, un hablante de una lengua absoluta tendría que poseer una capacidad de orientación superior, ya que tiene que estar actualizando continuamente su posición con respecto a los puntos cardinales. Brown y Levinson hallaron que así es. Transportaron a personas de comunidades absolutas a localizaciones novedosas y les pidieron que señalasen una serie de localizaciones distintas situadas a diversas distancias. Hallaron que podían hacerlo con relativa facilidad, mientras que los hablantes de lenguas relativas no podían hacerlo.

\subsubsection{Li y Gleitman vs. Brown y Levinson: la naturaleza del entorno triunfa sobre los efectos del lenguaje}

Li y Gleitman 2002 objetaron, primero, que pueden provocarse en anglohablantes nativos ambos modos dominantes de codificar la localización espacial -modos que Brown y Levinson pretenden que son causados por diferencias de codificación lingüística- y, segundo, que la naturaleza del entorno espacial triunfa sobre los efectos del lenguaje. Para mostrar esto último replicaron varias tareas del estilo de las de Brown y Levinson pero incluyeron condiciones en las que variaba el entorno para la tarea. Hallaron que la naturaleza del entorno tenía fuertes efectos sobre qué marco de referencia se reclutaba para codificar la localización en tareas no lingüísticas. En primer lugar, cuando se realizaba la tarea en interiores se resolvía con un sistema relativo, pero cuando tenía lugar en exteriores los resultados eran mixtos: se resolvía a veces con un sistema absoluto y otras con uno relativo. En segundo lugar, con la colocación de pistas espaciales se podía hacer que los sujetos diesen la respuesta de acuerdo con la pista espacial. Resultó en general que, a menores puntos de referencia espacial externos, mayor era la necesidad de emplear un sistema de referencia relativo; por el contrario, un entorno visual más rico propiciaba el uso de un marco absoluto. Esto sugería que los individuos son flexibles en su elección de marcos de referencia y que esas elecciones son mediadas por la naturaleza del entorno físico inmediato. Estos hallazgos se compadecían con un hecho conocido en etología: que, dependiendo de la riqueza del entorno espacial, los animales navegan usando un sistema de referencia centrado en el cuerpo o uno centrado en el entorno.

Los whorfianos han respondido que este argumento no tiene en cuenta que las diferencias en el marco de referencia espacial dominante son tipológicas y no locales: lenguas cuyos hablantes viven en entornos muy distintos pueden compartir el sistema de referencia espacial y lenguas de hablantes que viven en entornos similares pueden diferir en sus marcos de referencia. Por ejemplo, han alegado que los suizos, que 
viven en un entorno montañoso como los habitantes de Nepal, utilizan una lengua cuyo marco de referencia es distinto del de la lengua de los nepalíes. La cuestión que no parecen tener en cuenta quienes responden en estos términos es si el alemán se desarrolló inicialmente en un entorno montañoso o solo se extendió a él posteriormente. Levinson, Kita, Haun y Rasch 2002 también han respondido reproduciendo el experimento de Li y Gleitman pero introduciendo en él una tarea de rotación. Su conclusión fue que el resultado obtenido sigue mostrando que los marcos de referencia usados en el lenguaje de los hablantes encajan con los usados en su cognición no lingüística. Si es así, es una cuestión que, cuando menos, parece quedar abierta.

4.2.3. Retorno al problema de la circularidad: Munnich y Landau vs. Brown y Levinson

Munnich y Landau 2003 han formulado otra objeción contra Brown y Levinson: que, en la medida en que el lenguaje desempeña un papel en la determinación del marco de referencia, es posible que las tareas que se les propusieron a los sujetos fueran de hecho resueltas por ellos empleando el lenguaje. Ninguna de esas tareas se llevó a cabo excluyendo el uso de la codificación verbal. Tenían que transcurrir varios segundos para que los participantes girasen $180^{\circ}$ y asumiesen su nueva posición y ese tiempo sería suficiente para codificar verbalmente y ensayar las localizaciones de los objetos. En ese caso, se trataría de una tarea lingüísticamente mediada y no podría servir como prueba de que las representaciones espaciales no lingüísticas son conformadas por el lenguaje.

\subsection{Lenguas clasificadoras, forma y material}

4.3.1. Los efectos cognitivos de las pautas de marcación del plural en las lenguas clasificadoras

Lucy realizó un estudio comparativo del inglés y del maya yucateco, que es una lengua clasificadora (Lucy 1992b es la obra clave; cf. Lucy y Gaskins 2001, 2003; resúmenes de esta y de otras investigaciones se encuentran en Lucy 1996, 1997, 2005). En lenguas como el español o el inglés encontramos una distinción marcada entre términos generales contables, o de referencia dividida, como vaca, y términos generales no contables o de masa, como ganado. Una de sus características distintivas es que los hablantes señalan obligatoriamente el plural para los primeros, que se refieren a entidades discretas (vela/velas), pero no hay plural para los segundos, que se refieran a substancias o materiales 
genéricos (ganado/*ganados). En cambio, los hablantes de yucateca señalan opcionalmente los plurales para un número comparativamente menor de substantivos; no están obligados a hacerlo para ningún referente, aunque a menudo marcan el plural para objetos animados.

Hay una segunda diferencia entre lenguas como el español o el inglés, de una parte, y el yucateca, de la otra, en sus patrones de marcación del plural nominal. En las primeras, los numerales modifican directamente los términos de referencia dividida (dos vacas), pero los términos de masa requieren una unidad adecuada de individuación a la que se adjunta el numeral (dos cabezas de ganado). El yucateca, en cambio, en cuanto lengua clasificadora, exige que todas las construcciones cuantificadas sean suplementadas con un clasificador numeral que típicamente proporciona información sobre la forma o las propiedades materiales del referente (dos largas-delgadas velas, al cambio).

Lucy conjeturó que estas diferencias estructurales entre lenguas de uno y otro tipo deberían afectar la cognición de sus hablantes. Las diferencias entre los modos en que codifican los objetos las dos lenguas repercutirían en la realización de tareas no verbales por parte de los hablantes: los usuarios nativos de las dos lenguas tenderían a prestar atención a diferentes aspectos perceptivos de las entidades, especialmente de las entidades discretas e inanimadas. Según él, la forma de los objetos es la mejor indicación de una unidad de individuación y esto debería hacer que los anglohablantes nativos prestasen relativamente más atención a su forma que a su composición material. Por el contrario, los hablantes de una lengua clasificadora deberían centrarse relativamente más en la composición material que en la forma. Las lenguas clasificadoras aparecen en muchos lugares de América, de Asia y de África -chino, coreano, japonés, thai, algunas lenguas del grupo bantú, etc.-, por lo que cabría esperar que estas repercusiones tuvieran un alcance muy amplio.

Lucy y Gaskins sometieron a prueba esta conjetura con hablantes adultos y niños de ambas lenguas. En una tarea se les mostraron a doce hablantes de cada grupo quince tríadas de objetos familiares, cada una de las cuales constaba de un objeto original pivot y dos objetos alternativos, uno de la misma forma y uno del mismo material que el pivot, y se les pedía que los clasificaran: «¿Es el objeto X más parecido a A o más parecido a B?». En consonancia con las expectativas, resultó que en tareas experimentales no verbales de clasificación de tríadas de objetos, los adultos estadounidenses anglohablantes mostraron una fuerte preferencia por las clasificaciones basadas en la forma mientras que los hablantes adultos de yucateca mostraron una fuerte preferencia por las clasificaciones basadas en el material. Sin embargo, y muy significativamente, encontraron que en los hablantes de siete años de una y otra lengua se daba un sesgo inicial idéntico hacia la forma. Cuando alcanzaban la edad de nueve años, la pauta adulta ya era visible. Esto sugiere 
que la importancia de las categorías lingüísticas para la cognición aumenta entre los siete y los nueve años. Las dos comunidades comienzan agrupando diferentes tipos de referentes del mismo modo y acaban agrupándolos de modo diferente en función del tipo de lengua.

\subsubsection{Discrepancias}

\subsubsection{1. ¿Factores socioculturales?}

¿Se deben esas pautas diferenciales al lenguaje y no a factores socioculturales tales como la pobreza, la vida rural, las diferencias en los trasfondos culturales y educativos de los sujetos estadounidenses y de los sujetos mayas? Mazuka y Friedman 2000 cuestionaron la interpretación que hace Lucy de sus resultados y propusieron que una explicación sociocultural sería preferible. Llevaron a cabo un estudio similar al de Lucy en el que los sujetos eran, respectivamente, universitarios norteamericanos anglohablantes y universitarios japoneses (el japonés, como el yucateca, es una lengua con clasificadores) y resultó que su estudio no replicó los resultados de Lucy con los estudiantes japoneses.

Lucy se mantiene firme:

Se han confirmado consistentemente predicciones muy específicas a partir del lenguaje, aunque conciernen a patrones gramaticales diferentes, a funciones cognitivas diferentes y a materiales de estímulo diferentes. No se ha hecho aún ningún argumento cultural informado que explique esos resultados. Los niños no muestran esos patrones cognitivos hasta que se implantan los patrones lingüísticos, tanto hablantes educados como no educados muestran los patrones y los adultos que carecen de exposición al lenguaje no desarrollan los patrones de respuesta usuales. Finalmente, hay informes de preferencias similares por la clasificación material en los japoneses urbanos que tienen una lengua clasificadora pero cuya cultura y también estilo de vida educativo y urbano contrasta con los mayas (Lucy 2005, p. 307).

\subsubsection{2. ¿ ¿ntología universal o relatividad lingüistica?}

Las discrepancias anteriores pueden enmarcarse bajo el paraguas de una pregunta más amplia: ¿cómo llegan a adquirir los niños las categorías ontológicas? De acuerdo con una posición universalista, las categorías ontológicas se adquieren independientemente del lenguaje. Para los partidarios del relativismo lingüístico, esas categorías se alcanzan a través del aprendizaje de la lengua.

La posición de Lucy es claramente relativista. Como sucede en el trabajo de Mazuka y Friedman antes citado, una posición universalista ha sido defendida en un estudio de los psicólogos del desarrollo Soja, 
Carey y Spelke 1991. En su opinión, los niños están dotados de una apreciación innata de la distinción ontológica entre objetos discretos y substancias amorfas. En su estudio con niños anglohablantes de dos años que no han adquirido la distinción sintáctica contable/de masa han mostrado que, a pesar ello, son capaces de limitar los significados de palabras novedosas usando la distinción objeto/substancia. Al oír un substantivo novedoso en asociación con una entidad sólida y discreta (un objeto), lo extendían sobre la base de la forma; y al oír un substantivo novedoso en asociación con una substancia no sólida, lo extendían sobre la base de la identidad de materia, no de forma. Soja, Carey y Spelke concluyeron que se trata de un conocimiento universal, independientemente de si la lengua del niño marca la distinción en la gramática. Sin embargo, Imai y Gentner 1997 han apuntado que es posible que los niños de dos años sometidos a prueba ya hubiesen sido influidos por la lengua. De hecho, en un trabajo posterior Soja matizó su posición al encontrar que la sintaxis afectaba la ejecución de la tarea por parte de los niños, aunque la magnitud de su efecto no era lo bastante fuerte para cambiar la categorización por defecto de las entidades nombradas. Otros trabajos en esta línea parecían apuntar a una influencia del aprendizaje temprano de la lengua en la apreciación por los niños de la distinción objeto/substancia.

Para encarar los problemas que plantea, con respecto a la cuestión de la individuación, la disyuntiva entre posiciones universalistas y posiciones relativistas, Imai y sus colegas llevaron a cabo una serie de estudios con adultos y niños hablantes, respectivamente, de inglés y de japonés. En un primer trabajo, Imai y Gentner 1997 presentaron a los sujetos tres tipos de objetos. Los del primer tipo, los «objetos complejos», eran objetos reales con formas relativamente complejas y funciones diferenciadas, aunque sus funciones les eran desconocidas a los niños del estudio. Los del segundo tipo, los «objetos simples», tenían estructuras muy sencillas sin partes distintivas; estaban hechos de una substancia sólida como la cera, conformada en una forma muy simple, p. ej., en forma de riñón. El tercer tipo, las «substancias», estaba formado por materiales no sólidos, como la arena, dispuestos en formas diferenciadas e interesantes. Los resultados que obtuvieron confirmaban a nivel global la tesis de una ontología universal: al igual que los adultos y los niños anglohablantes, los hablantes de japonés, desde los dos años hasta la edad adulta, mostraban pautas de proyección del significado de palabras diferenciadas en las tareas con objetos complejos y con substancias. Sin embargo, encontraron también diferencias interlingüísticas, acordes con la propuesta de Lucy: en las tareas con substancias, mientras que los hablantes de japonés proyectaban el significado de la palabra sobre el material, los anglohablantes respondían al azar. En las tareas con objetos simples, por el contrario, mientras que los anglo- 
hablantes los trataban del mismo modo que los complejos y proyectaban el significado sobre la forma, los japoneses respondían al azar.

¿Pero resultarían ser a la postre efectos whorfianos lingüísticamente mediados o se reproducirían esas diferencias interlingüísticas cuando la tarea de proyección del significado de la palabra se reemplazase por una tarea de clasificación sin palabras? Para responder a esa cuestión, Imai y Mazuka 1997, 2003 (cf. Imai 2000) llevaron a cabo una serie de estudios ulteriores en los que los sujetos, japoneses y norteamericanos, eran sometidos a tareas de clasificación sin etiqueta verbal previa en las que a los sujetos se les pedía simplemente que dijeran cuál de dos estímulos es el mismo que la entidad estándar o es más semejante a ella. No es posible abordar en el espacio de este artículo los entresijos de los estudios que realizaron y los resultados que arrojaron. El siguiente párrafo puede tomarse a modo de resumen:

Aunque sostenemos que los conceptos ontológicos son universales, quisiéramos enfatizar que la diferencia en la conducta clasificatoria que se da entre hablantes de japonés y de inglés no debería despreciarse por carente de importancia para la cognición humana. Puesto que la percepción y la atención son elementos importantes de la cognición humana, si categorizaciones específicas de la lengua llevan realmente a los hablantes de inglés y a los hablantes de japonés a formar diferentes sesgos de atención hacia ciertos atributos perceptivos, entonces deberíamos retener una versión de la relatividad lingüística (Imai y Mazuka 2003, p. 458).

Imai y Mazuka insisten en que «la categorización gramatical específica del lenguaje lleva en cada lengua a los hablantes a formar hábitos de atender a un conjunto de atributos perceptivos que son sumamente relevantes y útiles para determinar la clase gramatical de una entidad» (Imai y Mazuka 2003, p. 457). Es una conclusión que, por su énfasis en los hábitos de atención, recuerda de algún modo el relativismo moderado que ha sido defendido por Slobin.

\section{ConClusión}

He citado en $\S 2$ textos que, en contra de lo que a veces parecen sugerir sus admiradores actuales, confirman que la posición de Sapir y de Whorf engloba cuatro tesis radicales que configuran lo que podría denominarse whorfianismo fuerte. En $\S 3$ he comenzado resumiendo brevemente el análisis contrastivo que presenta Whorf de la pluralidad y el tiempo en inglés y en hopi, y he tratado de mostrar que ese análisis está viciado por gruesas confusiones conceptuales y aquejado de un problema de circularidad. Whorf fue consciente además de un escollo, al que se refirió con la metáfora de la «calibración», y pretendió resolverlo 
apelando a procedimientos que ejemplifican el «efecto Ismael». Finalmente, y como es reconocido por muchos relativistas actuales, el whorfismo fuerte no es susceptible de ser sometido a control empírico.

En la segunda parte del trabajo, el enfoque no ha sido tanto crítico como descriptivo de parte del estado de la cuestión. He pretendido meramente dar cuenta de algunas de las principales líneas de investigación que se vienen llevando a cabo después de la resurrección de la hipótesis de la relatividad lingüística tras su muerte en manos del universalismo chomskyano y del modularismo fodoriano. La forma más suave de neowhorfianismo, la hipótesis del «pensar para hablar», es la propuesta por Slobin. Sin embargo, ha sido contestada por Gennari y sus colegas. Formas más fuertes de neowhorfianismo contemporáneo postulan efectos que no quedan confinados al lenguaje en uso, sino que se producen más allá del tiempo de hablar. He atendido a dos investigaciones que apuntan en esa dirección: los trabajos de Levinson y su grupo sobre los efectos cognitivos de las diferencias que se dan en los marcos de referencia espacial empleados por lenguas tipológicamente diversas y las investigaciones de Lucy y sus asociados sobre los efectos cognitivos de las pautas gramaticales distintivas de lenguas clasificadoras. De nuevo vuelve a suceder que no hay elementos suficientes para una respuesta taxativa a la cuestión de si esos pretendidos efectos han sido bien entendidos. Por un lado, Li y Gleitman han contestado los resultados de Levinson y Brown y, en cuanto a los resultados de Lucy, algunos investigadores han sugerido que las diferencias encontradas por él pueden deberse predominantemente no a factores lingüísticos, sino a factores socioculturales, mientras que otros investigadores han llegado a resultados mixtos.

En suma, el whorfianismo clásico es conceptualmente confuso y no es sometible a control empírico; por el contrario, las formas contemporáneas de relativismo lingüístico están basadas en investigaciones empíricas controladas, pero los resultados que se han alcanzado aún distan de haber logrado un consenso entre los estudiosos.

\section{REFERENCIAS BIBLIOGRÁFICAS}

BLACK, M. (1962): Models and metaphors: Studies in language and philosophy, Ithaca, N.Y., Cornell University Press (trad. esp.: Modelos y metáforas, Madrid, Tecnos, 1968).

Brown, R. y Gilman, A. (1960): «The pronouns of power and solidarity», en Sebeok, T. (ed.), Aspects of style in language, Cambridge, Mass., MIT Press, pp. 253-277.

Brown, M. y LeVInson, S. C. (1993): «Linguistic and nonlinguistic coding of spatial arrays: Explorations in Mayan cognition», Working paper 24, Nimega, Cognitive Anthropology Research Group, Max Planck Institute for Psycholinguistics. 
CARROLL, J. B. (1956): Language, thought and reality: selected writings of Benjamin Lee Whorf, Cambridge, Mass., MIT Press.

Fodor, J. J. (1975): The language of thought, Nueva York, Thomas Y. Crowell (trad. esp.: El lenguaje del pensamiento, Madrid, Alianza, 1984).

Gennari, S. P.; Sloman, S. A.; Melt, B. C. y Fitch, W. T. (2002): «Motion events in language and cognition», Cognition 83, pp. 49-79.

Humboldt, W. von (1836): Über die Verschiedenheit des menschlichen Sprachbaues und ihren Einfluss auf die geistige Entwickelung des Menschengeschlechts, (Abhandlugen der Akademie der Wissenschaften zu Berlin), Dümmlers Verlag; reimpreso en 1960 (trad. esp.: Sobre la diversidad de la estructura del lenguaje humano y su influencia sobre el desarrollo espiritual de la humanidad, Madrid, Anthropos, 1990).

Hymes, D. H. (ed.) (1949): The selected writings of Edward Sapir in culture and society: A reader in linguistics and anthropology, Berkeley, University of California Press.

- (ed.) (1964): Language in culture and society: A reader in linguistics and anthropology, Nueva York, D. Harper \& Row.

ImAI, M. (2000): «Universality and cross-linguistic difference in the construal of individuation», trabajo presentado en el Language and Thought Symposium, Durham.

- y Gentner, D. (1997): «A crosslinguistic study of early word meaning: Universal ontology and linguistic difference», Cognition 62, pp. 169-200.

- y Mazuka, R. (1997): «A cross-linguistic study on the construal of individuation in linguistic and non-linguistic contexts», trabajo presentado en la reunión de la Society for Research in Child Development, Washington, D. C.

- (2003): «Reevaluating linguistic relativity: Language-specific categories and the role of universal ontological knowledge in the construal of individuation", en Gentner, D. y Goldin-Meadow, S. (eds.), Language in mind: Advances in the study of language and thought, Cambridge, Mass., MIT Press, pp. 429-464.

LENNEBERG, E. (1953): «Cognition in ethnolinguistics», Language 29, pp. 463-471.

LeVinson, S. C. (2003): Space in language and cognition: Explorations in cognitive diversity, Cambridge, Cambridge University Press.

-; Kita, S.; Haun, D. y Rasch, B. (2002): «Re-turning the tables: Language affects spatial reasoning», Cognition 84, pp. 155-188.

Li, P. y Gleitman, L. (2002): «Turning the tables: Language and spatial reasoning», Cognition 83, pp. 265-294.

LuCY, J. A. (1992a): Language diversity and thought: A reformulation of the linguistic relativity hypothesis, Cambridge, Cambridge University Press.

- (1992b): Grammatical categories and cognition: A case study of the linguistic relativity hypothesis, Cambridge, Cambridge University Press.

- (1996): «The scope of linguistic relativity: An analysis and review of empirical research», en Gumperz, J. J. y Levinson, S. C. (eds.), Rethinking linguistic relativity, Cambridge, Cambridge University Press, pp. 37-69.

- (1997): «Linguistic relativity», Annual Reviews of Anthropology 26, pp. 291-312.

- (2005): «Through the window of language: assessing the influence of language diversity on thought», Theoria 54, pp. 299-309. 
- y Gaskins, D. (2001): «Grammatical categories and the development of classificational preferences: a comparative approach», en Levinson, S. C. y Bowerman, M. (eds.), Language acquisition and conceptual development, Cambridge, Cambridge University Press, pp. 275-283.

- (2003): «Interaction of language type and referent type in the development of nonverbal classification preferences», en Gentner, D. y GoldinMeadow, S. (eds.), Language in mind: Advances in the study of language and thought, Cambridge, Mass., MIT Press, pp. 465-492.

MAZUKA, R. y Friedman, R. (2000): «Linguistic relativity in Japanese and English: Is language the primary determinant in object classification?», Journal of East Asian Linguistics 9, pp. 353-377.

Melt, B. C.; Sloman, S. A. y Gennari, S. P. (2003): «Speaking versus thinking about objects and actions», en Gentner, D. y Goldin-Meadow, S. (eds.), Language in mind: Advances in the study of language and thought, Cambridge, Mass., MIT Press, pp. 81-111.

MunNich, E. y LANDAU, B. (2003): «The effects of spatial language on spatial representation: setting some boundaries», en Gentner, D. y Goldin-Meadow, S. (eds.), Language in mind: Advances in the study of language and thought, Cambridge, Mass., MIT Press, pp. 113-155.

Pinker, S., (1989): Learnability and cognition: The acquisition of argument structure, Cambridge, Mass., MIT Press.

Rossi-Landi, F. (1973): Ideologies of linguistic relativity, La Haya, Mouton.

SAPIR, E. (1931): «Conceptual categories in primitive languages», Science 74, pp. 578-562.

SLOBIN, D. I. (1987): «Thinking for speaking», Proceedings of the Berkeley Linguistics Society 13, pp. 435-444.

- (1991): «Learning to think for speaking: Native language, cognition and rhetorical Style», Pragmatics 1, pp. 7-25.

- (1996a): «Two ways to travel: Verbs of motion in English and Spanish», en Shibatani, M. y Thompson, S. A. (eds.), Grammatical constructions: Their form and meaning, Oxford, Oxford University Press, pp. 195-220.

- (1996b): «From 'thought and language' to 'thinking for speaking'», en Gumperz, J. J. y Levinson, S. C. (eds.), Rethinking linguistic relativity, Cambridge, Cambridge University Press, pp. 70-96.

- (2000): «Verbalized events: A dynamic approach to linguistic relativity and determinism», en Niemeier, S. y Dirven, R. (eds.), Evidence for linguistic relativity, Ámsterdam, John Benjamins, pp. 107-138.

- (2003): «Language and thought online: Cognitive consequences of linguistic relativity», en Gentner, D. y Goldin-Meadow, S. (eds.), Language in mind: Advances in the study of language and thought, Cambridge, Mass., MIT Press, pp. 157-192.

SoJA, N. N. (1992): «Inferences about the meanings of nouns: the relationship between perception and syntax», Cognitive Development 7, pp. 109-136.

—; Carey, S. y Spelke, E. S. (1991): «Ontological categories guide young children's inductions of word meaning: Object terms and substance terms", Cognition 38, pp. 179-211. 
Stove, D. (1991): «Epistemology and the Ishmael effects», The Plato cult and other philosophical follies, Oxford, Blackwell.

TALMY, L. (1985): «Lexicalization patterns: Semantic structure in lexical forms», en Shopen T. (ed.), Language typology and syntactic description, vol. III, Grammatical categories and the lexicon, Cambridge, Cambridge University Press.

- (1991): «Path to realization: a typology of event conflation», Proceedings of the Berkeley Linguistics Society 17, pp. 480-519.

- (2000): Toward a cognitive semantics, Cambridge. Mass., MIT Press. 